\title{
Meat consumption trends and relationship with body composition measurements in adolescents and young adults: the Northern Ireland Young Hearts Project
}

\author{
S. Watson ${ }^{1}$, S. Brennan ${ }^{2}$, J.V. Woodside ${ }^{2}$, M. Cantwell ${ }^{2}$, C.A. Boreham ${ }^{3}$, C.E. Neville ${ }^{2}$, \\ Y.Y. Gong ${ }^{1}$ and G.J. Cuskelly ${ }^{1}$ \\ ${ }^{1}$ Institute for Global Food Security, School of Biological Sciences, Queen's University Belfast, Belfast BT9 5BN, UK, \\ ${ }^{2}$ Centre for Public Health, School of Medicine, Dentistry and Biomedical Sciences, Queen's University Belfast, \\ Belfast BT12 6BA, UK and ${ }^{3}$ Institute for Sport and Health, University College Dublin, Dublin, Republic of Ireland
}

Identifying risk factors that contribute to the onset of overweight and obesity is a key public health priority. It has been hypothesised that high consumption of red meat and processed meat can increase the risk of overweight/obesity (1), likely owing to their high energy density. The objectives of the study were to explore trends in meat intake of adolescents over a 10 -yr period, and to examine the cross-sectional and longitudinal relationships between red meat, processed meat and total meat intake, and body composition measurements.

Analyses were based on data from the Young Hearts (YH) project (3 cohorts), which was established to examine risk factors associated with cardiovascular disease of young people living in Northern Ireland. In 1989/1990, 12 and 15-yr olds (n = 1015) were randomly recruited from 16 post-primary schools (YH1) across Northern Ireland (2). In 1997/1999, 489 participants from YH1 were followed-up (mean age: 22.6 yrs) (YH3), achieving a 48.2 \% response rate (3). In 2000, a further cross-sectional survey (YH2000) was carried out; during which 12 and 15 -yr olds $(n=2017)$ were randomly recruited from 36 post-primary schools $(4)$. Dietary intake was assessed by a 7-d diet history. Meat groups were generated from the dietary data and included: red meat, processed meat, poultry, fish, Indian/Chinese food and total meat. Body composition measurements included BMI and waist circumference (WC).

Adolescent processed meat intake decreased over the 10-yr period, between YH1 and YH2000 (45.24 vs. 38.50 g/d; $P<0 \cdot 001)$, while intakes of poultry $(25.32$ vs. $33.67 \mathrm{~g} / \mathrm{d} ; \mathrm{P}<0.001)$, Indian/Chinese $(30.89 \mathrm{vs} .51 .35 \mathrm{~g} / \mathrm{d} ; P<0.001)$ and total meat (127.34 vs. $134.16 \mathrm{~g} /$ $\mathrm{d} ; P=0.01)$ increased. Cross-sectional results showed that meat intake was not associated with BMI or WC in adolescents or young adults, after adjusting for age, sex, social class, tanner stage (adolescents only) energy intake and physical fitness. For the longitudinal analysis, participants were divided (median split) into high or low meat intake groups (red, processed and total meat) at adolescence (YH1) and at young adulthood (YH3). To summarise the change in each of these meat groups between YH1 and YH3, four categories were created, and the relationship with young adult (YH3) BMI and WC examined (see table below). Having high intakes of red meat at both YH1 and YH3, compared to low intakes at both time points was associated with a $2.91 \mathrm{~cm}$ increase in young adult WC. Similar comparisons for processed meat and total meat were associated with $2.74 \mathrm{~cm}$ and $2.94 \mathrm{~cm}$ increases in young adult WC, respectively. An increase in young adult BMI of $0.82 \mathrm{~kg} / \mathrm{m}^{2}$ was observed for those with high intakes of total meat at YH1 and YH3, compared to those with low intakes at both time points.

\begin{tabular}{|c|c|c|c|c|c|c|c|}
\hline & \multirow[t]{2}{*}{$\begin{array}{l}\text { Low intake YH1-low } \\
\text { intake YH3 }\end{array}$} & \multicolumn{2}{|c|}{$\begin{array}{l}\text { Low intake YH1-high intake } \\
\text { YH3 }\end{array}$} & \multicolumn{2}{|c|}{$\begin{array}{l}\text { High intake YH1- low } \\
\text { intake YH3 }\end{array}$} & \multicolumn{2}{|c|}{$\begin{array}{l}\text { High intake YH1-high } \\
\text { intake YH3 }\end{array}$} \\
\hline & & $B$ & $95 \% \mathrm{CI}$ & $B$ & $95 \% \mathrm{CI}$ & $B$ & $95 \% \mathrm{CI}$ \\
\hline \multicolumn{8}{|c|}{ YH3 BMI $\left(\mathrm{kg} / \mathrm{m}^{2}\right)$} \\
\hline Red meat & ref & 0.40 & $-0 \cdot 39,1 \cdot 18$ & $0 \cdot 17$ & $-0 \cdot 61,0 \cdot 94$ & 0.58 & $-0.17,1.33$ \\
\hline Processed meat & ref & -0.02 & $-0 \cdot 82,0 \cdot 77$ & 0.78 & $0 \cdot 01,1 \cdot 54^{*}$ & $0 \cdot 50$ & $-0.27,1.26$ \\
\hline Total meat & ref & 0.68 & $-0 \cdot 10,1 \cdot 45$ & 0.00 & $-0 \cdot 76,0.77$ & 0.82 & $0 \cdot 08,1.55^{*}$ \\
\hline \multicolumn{8}{|l|}{ YH3 WC (cm) } \\
\hline Red meat & ref & $2 \cdot 27$ & $0 \cdot 04,4 \cdot 50^{*}$ & $2 \cdot 17$ & $-0.03,4.38$ & $2 \cdot 91$ & $0.79,5 \cdot 03^{* *}$ \\
\hline Processed meat & ref & 1.65 & $-0 \cdot 65,3 \cdot 95$ & 3.00 & $0 \cdot 79,5 \cdot 22 * *$ & 2.74 & $0.53,4.95^{* *}$ \\
\hline Total meat & ref & $2 \cdot 62$ & $0 \cdot 39,4 \cdot 86^{*}$ & 0.59 & $-1 \cdot 61,2 \cdot 80$ & 2.94 & $0 \cdot 81,5 \cdot 06^{* *}$ \\
\hline
\end{tabular}

Data were analysed using multivariate regression and presented as Beta values $(95 \% \mathrm{CI}) . * \mathrm{P}<0 \cdot 05, * * \mathrm{P}<0 \cdot 01, * * * \mathrm{P}<0 \cdot 001$. Adjusted for age, sex, social class, tanner stage, energy intake, VO2 max and adolescent BMI.

Dietary guidelines and intervention programs for reducing meat intake should be implemented early in life as this may assist in preventing obesity in adulthood.

1. Rouhani MH, Salehi-Abargouei A, Surkan PJ et al. (2014) Obes Rev 15, 740-748.

2. Boreham C, Savage JM, Primrose D et al. (1993) Arch Dis Child 68, 182-186.

3. Gallagher AM, Savage JM, Murray LJ et al. (2002) Public Health 116, 332-340.

4. McGartland C, Robson P, Murray LJ et al. (2003) J Bone Miner Res 18, 1563-1569 